\title{
Leishmania isoenzyme polymorphisms in Ecuador: Relationships with geographic distribution and clinical presentation
} Manuel Calvopina*1, Rodrigo X Armijos ${ }^{2}$, Jorge D Marco ${ }^{1}$, Hiroshi Uezato ${ }^{3}$, Hirotomo Kato ${ }^{4}$, Eduardo A Gomez ${ }^{5}$, Masataka Korenaga1, Paola A Barroso ${ }^{1}$, Tatsuyuki Mimori ${ }^{6}$, Philip J Cooper ${ }^{7}$, Shigeo Nonaka ${ }^{3}$ and Yoshihisa Hashiguchi ${ }^{1}$

Address: ${ }^{1}$ Department of Parasitology, Kochi Medical School, Kochi University, Kochi 783-8505, Japan, ${ }^{2}$ Health Sciences Program, College of Health Sciences, University of Texas at El Paso, El Paso, TX 79902-0581, USA, ${ }^{3}$ Department of Dermatology, Faculty of Medicine, University of the Ryukyus, Okinawa 903-0215, Japan, ${ }^{4}$ Department of Veterinary Hygiene, Faculty of Agriculture, Yamaguchi University, Yamaguchi 753-8515, Japan, ${ }^{5}$ Departamento de Medicina Tropical, Facultad de Medicina, Universidad Católica Santiago de Guayaquil, Ecuador, ${ }^{6}$ Department of Microbiology, School of Health Sciences, Kumamoto University, Kumamoto 862-0976, Japan and ${ }^{7}$ Laboratorio de Investigaciones, Hospital Pedro Vicente Maldonado, Pichincha Province, Ecuador; and Centre for Infection, St George's University of London, London, UK

Email: Manuel Calvopina* - mcalvopina@hotmail.com; Rodrigo X Armijos - rxarmijos@utep.edu;

Jorge D Marco - diegomarcoar@yahoo.com.ar; Hiroshi Uezato - huezato@med.u-ryukyu.ac.jp; Hirotomo Kato - katoh@yamaguchi-u.ac.jp; Eduardo A Gomez - egolandires@yahoo.es; Masataka Korenaga - korenaga@med.kochi-ac.jp; Paola A Barroso - paobarunsa@hotmail.com; Tatsuyuki Mimori - mimori@hs.kumamoto-u.ac.jp; Philip J Cooper - pcooper@ecnet.ec; Shigeo Nonaka - shigeo@med.u-ryukyu.ac.jp; Yoshihisa Hashiguchi - hashiguy@med.kochi-u.ac.jp

* Corresponding author

Published: 13 September 2006

BMC Infectious Diseases 2006, 6:139 doi:10.1 186/147/-2334-6-139
Received: 13 May 2006

Accepted: 13 September 2006

This article is available from: http://www.biomedcentral.com/I47I-2334/6/I39

(c) 2006 Calvopina et al; licensee BioMed Central Ltd.

This is an Open Access article distributed under the terms of the Creative Commons Attribution License (http://creativecommons.org/licenses/by/2.0), which permits unrestricted use, distribution, and reproduction in any medium, provided the original work is properly cited.

\begin{abstract}
Background: Determinants of the clinical presentation of the leishmaniases are poorly understood but Leishmania species and strain differences are important. To examine the relationship between clinical presentation, species and isoenzyme polymorphisms, 56 Leishmania isolates from distinct presentations of American tegumentary leishmaniasis (ATL) from Ecuador were analyzed.
\end{abstract}

Methods: Isolates were characterized by multilocus enzyme electrophoresis for polymorphisms of II isoenzymes. Patients were infected in four different ecologic regions: highland and lowland jungle of the Pacific coast, Amazonian lowlands and Andean highlands.

Results: Six Leishmania species constituting $2 \mathrm{I}$ zymodemes were identified: L. (Viannia) panamensis ( $2 \mathrm{I}$ isolates, 7 zymodemes), L. (V.) guyanensis (7 isolates, 4 zymodemes), L. (V.) braziliensis (5 isolates, 3 zymodemes), L. (Leishmania) mexicana (II isolates, 4 zymodemes), L. (L.) amazonensis ( 10 isolates, 2 zymodemes) and L. (L.) major (2 isolates, I zymodeme). L. panamensis was the species most frequently identified in the Pacific region and was associated with several clinical variants of cutaneous disease (CL); eight cases of leishmaniasis recidiva cutis (LRC) found in the Pacific highlands were associated with 3 zymodemes of this species. Mucocutaneous leishmaniasis found only in the Amazonian focus was associated with 3 zymodemes of $L$. braziliensis. The papular variant of $C L$, Uta, found in the Andean highlands was related predominantly with a single zymodeme of $L$. mexicana.

Conclusion: Our data show a high degree of phenotypic variation within species, and some evidence for associations between specific variants of ATL (i.e. Uta and LRC) and specific Leishmania zymodemes. This study further defines the geographic distribution of Leishmania species and clinical variants of ATL in Ecuador. 


\section{Background}

Ecuador straddles the Andes and is crossed by the Equator and is home to extremely diverse ecologic conditions. American tegumentary leishmaniasis (ATL) in Ecuador occurs throughout the tropical Amazon and Pacific coastal regions and in some inter-Andean valleys. According to the Ecuadorian Ministry of Health, human cases have been reported from 20 of the country's 22 provinces and an estimated 3.1 to 4.5 million people are considered to be at risk of infection with 3,000-4,500 new cases occurring annually [1].

Differences in clinical presentations and severity of the leishmaniases are explained by interactions between particular molecular and biologic characteristics of different Leishmania species, host genetics and immunity and, environmental factors $[2,3]$. Although it is generally accepted that major clinical forms of ATL may be caused by specific Leishmania species, the relationship between Leishmania zymodemes and clinical presentation remains unclear [4]. To date, most studies investigating the relationship between polymorphisms and clinical disease have provided little evidence for strong associations [5-9], probably because of the substantial variability among the etiological agents of ATL at the subgenus level, with at least 15 species described [10]. In addition, Leishmania species in the New World are highly diverse genetically as reported from Brazil, Colombia, French Guiana and Peru $[7-9,11,12]$.

ATL in Ecuador constitutes a group of diseases with a wide spectrum of clinical variations $[13,14]$ and atypical presentations [15]. Six Leishmania species had been identified as causative agents of ATL in this country: L. (Viannia) braziliensis, L. (V.) panamensis, L. (V.) guyanensis, L. (Leishmania) mexicana, $L$. (L.) amazonensis and $L$. (L.) major-like $[13,16-19]$. However, few parasite isolates have been analyzed for genetic diversity or phenotypic characterization by isoenzyme polymorphisms and a survey of 28 human stocks isolated from single and multiple CL ulcers showed a high degree of genetic diversity within $L$. panamensis/L. guyanensis species [20].

The characterization and identification of causative species and zymodeme phenotypes, and their geographic distribution together with the clinical disease caused provides important information for the design, prioritization (e.g. according to risk of mucosal disease), and implementation of control programs for this important disfiguring parasitic infection. In the current study, we report the diversity of Leishmania species and zymodeme phenotypes isolated from clinical lesions from 56 patients with varying clinical presentations of ATL from 4 different geographic regions of Ecuador.

\section{Methods \\ Origin, sampling, isolation and cultivation of Leishmania stocks}

Twenty-nine parasite isolates included in this study were sampled between 2000 and 2001 in the Leishmaniasis Reference Center of the Central University, and the remaining isolates were obtained during an active search for patients infected in the Pacific highlands and lowlands, Amazonian lowlands and, in the Andean region. None of the patients had been living or infected outside Ecuador.

Ecologically, (i) the highlands (500-1,000 m altitude) and (ii) lowlands $(<500 \mathrm{~m})$ of the Pacific region are subtropical and tropical humid rainforest, respectively. Both zones are predominantly forest cleared for cattle ranching or cultivation of banana, cocoa, coffee, and African palm oil; the ambient temperature ranges $15-22^{\circ} \mathrm{C}$ in the highlands and $24-28^{\circ} \mathrm{C}$ in the lowlands. (iii) Amazonian lowlands (100-500 m elevation) are located East of the Andes and are covered by dense tropical rainforest with temperatures varying $25-29^{\circ} \mathrm{C}$ and high humidity. (iv) interAndean valleys (Huigra and Paute) are at 1,200-2,500 m elevation with temperatures ranging from $12-18^{\circ} \mathrm{C}$ and scarce vegetation (Figure 1).

Leishmania isolates were obtained by aspiration of lesions from patients with suspected CL or MCL and aspirates were cultivated directly in USMARU biphasic medium as described previously [21]. The parasites were bulk-cultured in RPMI-1640 medium with 20\% fetal calf serum. They were harvested by centrifugation $(10,000 \mathrm{~g} \times 10$ $\min$ ) and washed thrice in phosphate-buffered saline ( $\mathrm{pH}$ 7.2) as described [22]. Parasites pellets were stored at $80^{\circ} \mathrm{C}$ until isoenzyme analysis. All patients provided written consent to participate in the study and the protocol was approved by the ethical committee of the Central University of Quito, Ecuador.

\section{Isoenzyme characterization}

Sample preparation, electrophoresis and staining procedures were followed as described $[22,23]$. Cellulose acetate plates (Sebiagel, Moulineaux, France) were used and assays were repeated twice. In this study, we have assayed each Ecuadorian isolate and WHO reference strain for the activity of the following 11 enzymatic systems: malate dehydrogenase (EC 1.1.1.37, MDH); malic enzyme (EC 1.1.1.40, ME); 6-phosphogluconate dehydrogenase (EC 1.1.1.44, 6-PGD); glucose-6-phosphate dehydrogenase (EC 1.1.1.49, G-6-PD); mannose phosphate isomerase (EC 5.3.1.8, MPI); glucose phosphate isomerase (EC 5.3.1.9, GPI); alanine aminotransferase (EC 2.6.1.2, ALAT); aspartate aminotransferase (EC 2.6.1.1, ASAT); phosphoglucomutase (EC 2.7.5.1, PGM); pyruvate kinase (EC 2.7.1.40, PK) and nucleoside hydrolase (inosine) (EC 


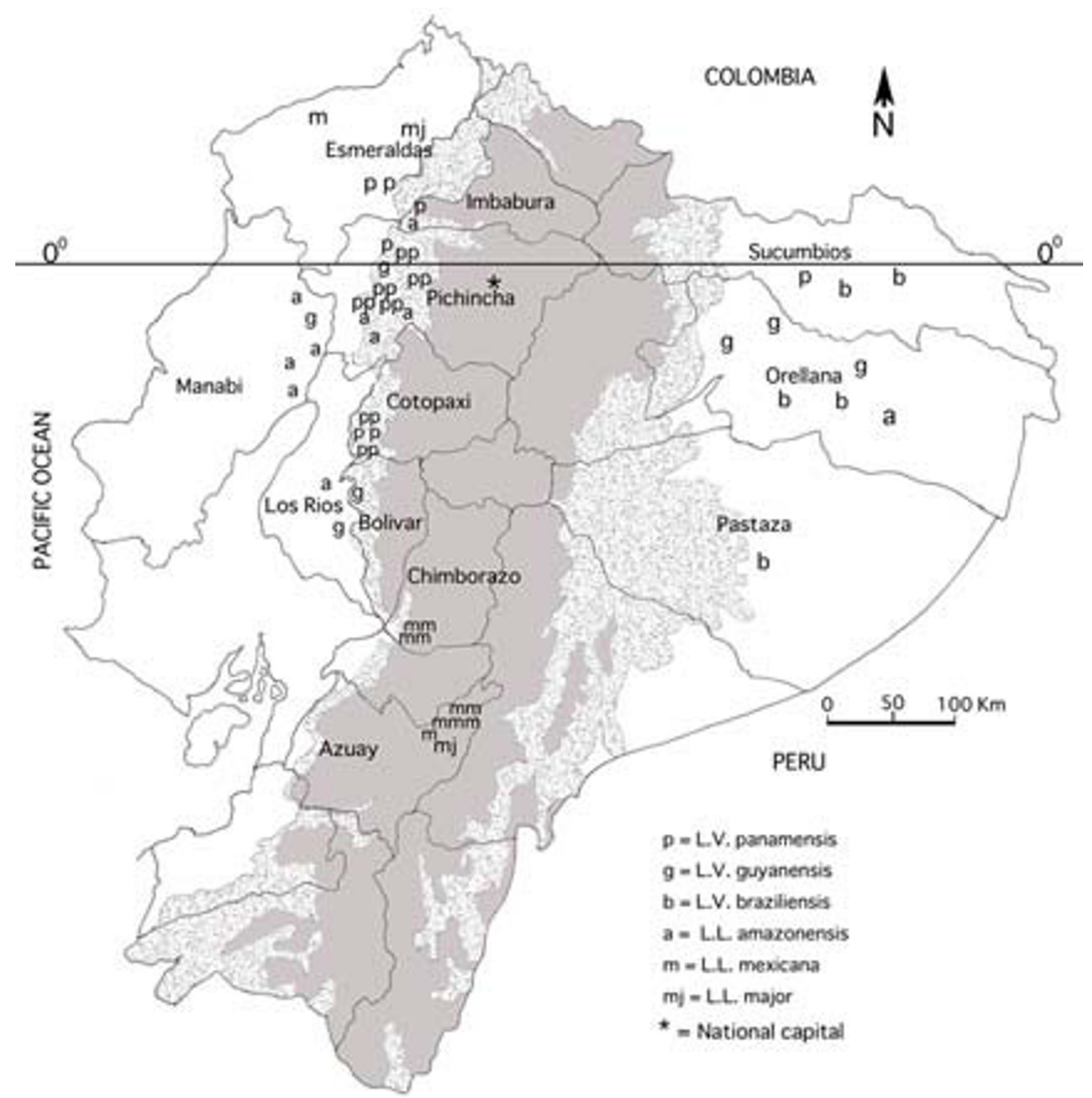

\section{Figure I}

Map of Ecuador showing the geographic locations (regions and provinces) of Leishmania species identified in this study. The shaded area shows the Andean plateau (>1,000 m altitude). Dotted areas show highland jungle or Andean slopes (400-I,000 m elevation). The tropical rainforest of Pacific coastal and Amazon regions are shown in white. Each letter represents one isolate. 
2.4.2, NHi). Nine selected WHO reference strains, obtained from the cryobank of London School of Hygiene and Tropical Medicine, were used in this study for species identification: L. (V.) braziliensis (MHOM/BR/75/ M2903); L. (V.) panamensis (MHOM/PA/71/LS94); L. (V.) guyanensis. (MHOM/BR/75/M4147); L. (V.) peruviana (MHOM/PE/84/LC39); L. (V.) naiffi (MDAS/BR/79/ M5533); L. (L.) mexicana (MNYC/BZ/62/M379); L. (L.) amazonensis (MHOM/BR/73/M2269); L. (L.) chagasi (MHOM/BR/74/M2682) and, L. (L.) major (MHOM/SU/ 73/5ASKH).

\section{Data analysis}

Each isolate was assessed according to the position of the electrophoretic bands for all 11 enzymes. Each electrophoretic band was considered as a separate character and was numbered from the most distal to the anodic point in each zymogram. Zymodemes were identified according to the pattern of electrophoretic profiles for the 11 enzymes as previously described [24]. Identification of the Ecuadorian isolates was performed by comparing electrophoretic profiles with WHO reference Leishmania strains. Hierarchical cluster analysis was used to summarize the relationships between zymodemes using Jaccard's coefficient of similarities [25]. Phenograms were constructed by analyzing each electrophoretic band as a unit character, by construction of a matrix with the presence or absence of electrophoretic bands using the interactive molecular evolutionary genetics analysis (MEGA) software, version 3.0 [26].

\section{Results}

A total of fifty-six Leishmania isolates were obtained from fifty-six different subjects with ATL in Ecuador. Individuals were infected in four different bioclimatic geographic areas in 12 provinces (Figure 1). Of the 56 subjects studied, 52 presented with cutaneous lesions with a wide variety of clinical presentations: 30 ulcers, 9 small papules or Uta-like, 8 leishmaniasis recidiva cutis (LRC), 2 sporotrichoid or pian-bois, 1 disseminated (DL), 1 erysipeloid and 1 with diffuse cutaneous leishmaniasis (DCL). The remaining four presented with mucocutaneous leishmaniasis (MCL) or espundia.

In total, six Leishmania species were identified revealing 21 different zymodemes (Table 1). Of the 56 isolates, 21 $(37.5 \%)$ were typed as $L$. panamensis revealing 7 different zymodemes; $11(19.6 \%)$ as L. mexicana with 4 zymodemes; $10(17.8 \%)$ as L. amazonensis with 2 zymodemes; $7(12.5 \%)$ as L. guyanensis with 4 zymodemes; 5 (8.9\%) as L. braziliensis with 3 zymodemes and 2 (3.6\%) as L. major with one zymodeme. The zymodeme composition is shown in Table 2. None of the Leishmania zymodemes present in Ecuador of L. braziliensis, L. mexicana and $L$. major were identical to the Leishmania WHO reference strains and, none of the Ecuadorian stocks were matched to the WHO reference strains for $L$. (V.) peruviana, L. (V.) naiffi or $L$. (L.) chagasi (Figure $2 \mathrm{~A}$ and $2 \mathrm{~B}$ ).

There was some evidence for geographic restriction of Leishmania species: L. panamensis, L. guyanensis and L. amazonensis were isolated from 3 regions (not from the inter-Andean); L. braziliensis was isolated only from the Amazon lowlands; L. mexicana was identified almost exclusively in the inter-Andean region, although one isolate of this species was identified in the Pacific lowlands (Figure 1).

Findings for each of the 56 isolates are provided in Table 1 showing Leishmania species and zymodeme identified for each of the 4 ecologic regions in Ecuador. In the Pacific coastal highlands, 25 human isolates were studied, 12 were obtained from cutaneous ulcers and 13 from atypical presentations (LRC, sporotrichoid, erysipeloid and DL); three species, L. panamensis, L. guyanensis and L. amazonensis and 10 different zymodemes were identified as causative organisms. Three zymodemes of L. panamensis (Z3, Z4 and Z5) were the only parasites associated with LRC (See Figure 3 for clinical characteristics and Figure 2A for zymodemes and their distance with WHO L. panamensis). Interestingly, Z3 was identified also in other atypical variants of CL as disseminated and erysipeloid. Ulcers were associated with 8 zymodemes from the 3 species circulating in Pacific highlands. In the Pacific lowlands, 10 isolates were studied, of which 9 came from single or multiple CL ulcers and 1 from a patient with DCL. Five species with 7 different zymodemes were identified from these isolates. The case of DCL was associated with Z17 of L. mexicana.

Ten isolates were analyzed from the Amazon lowlands of which four came from MCL (Figure 4) and 6 from CL ulcers. Four species and 6 zymodemes were identified. Three zymodemes of L. braziliensis (Z6, Z9 and Z10) were associated with the isolates from MCL patients. Eleven isolates were studied from the inter-Andean valley region, 7 isolates from Paute and 4 from Huigra, of which 10 were identified as 3 zymodemes (Z18, Z19 and Z20) of L. mexicana and one a single zymodeme of L. major. Most clinical lesions in this region were crusted papules (Uta-like) lesions (Figure 5).

The phenograms (Figure 2) show that the Leishmania subgenera, Viannia and Leishmania, form distinct groups. The genetic distance (Jaccard distances) between the two subgenera was over 0.9 . Figure $2 \mathrm{~A}$ shows the relationships between different zymodemes isolated from the subtropical and tropical Pacific and Amazon geographic regions, while Figure $2 \mathrm{~B}$ shows the same for the inter-Andean zymodemes. Different species were considered have Jac- 
Table I: Distribution of Leishmania species and zymodemes by lesion type and geographic origin

\begin{tabular}{|c|c|c|c|c|c|}
\hline \multirow[b]{2}{*}{ Leishmania species } & \multirow[b]{2}{*}{ Zymodeme } & \multicolumn{4}{|c|}{ Geographical region } \\
\hline & & Pacific lowlands & Pacific highlands & inter-Andean valleys & Amazonian lowlands \\
\hline \multirow[t]{2}{*}{ L. L. amazonensis } & ZI & ulcer (I) & ulcer (I) & - & ulcer (I) \\
\hline & Z2 & ulcer (4) & ulcer (3) & - & - \\
\hline \multirow[t]{7}{*}{ L. V. panamensis } & $\mathrm{Z3}$ & - & $\begin{array}{l}\text { LRC (4), ulcer (I), E } \\
\text { (I), DL (I) }\end{array}$ & - & - \\
\hline & Z4 & - & $\operatorname{LRC}(2)$ & - & - \\
\hline & Z5 & - & LRC (2), ulcer (I) & - & - \\
\hline & Z7 & ulcer (I) & - & - & - \\
\hline & Z8 & ulcer (I) & ulcer (I) & - & ulcer (I) \\
\hline & ZI5 & - & $S(I)$ & - & - \\
\hline & $\mathrm{Z} 16$ & - & $\begin{array}{c}\text { ulcer (2), papular (I), } \\
\text { S (I) }\end{array}$ & - & - \\
\hline \multirow[t]{4}{*}{ L. V. guyanensis } & ZII & ulcer (I) & - & - & - \\
\hline & $\mathrm{Z} 12$ & - & - & - & ulcer (3) \\
\hline & $\mathrm{ZI3}$ & - & ulcer (2) & - & - \\
\hline & ZI4 & - & ulcer (I) & - & - \\
\hline \multirow[t]{3}{*}{ L. V. braziliensis } & $\mathrm{Z} 6$ & - & - & - & ulcer (I), MCL (I) \\
\hline & Z9 & - & - & - & $M C L(I)$ \\
\hline & Z10 & - & - & - & MCL (2) \\
\hline \multirow[t]{4}{*}{ L. L. mexicana } & ZI7 & $\mathrm{DCL}(\mathrm{I})$ & - & - & - \\
\hline & $\mathrm{Z} 18$ & - & - & ulcer (3), papular (I) & - \\
\hline & Z19 & - & - & papular (I) & - \\
\hline & Z20 & - & - & papular (5) & - \\
\hline L. L. major & $\mathrm{Z2I}$ & ulcer (I) & - & papular (I) & - \\
\hline
\end{tabular}

Number of isolates are shown in parentheses. DCL, diffuse cutaneous leishmaniasis; LRC, leishmaniasis recidiva cutis; MCL, mucocutaneous leishmaniasis; S, sporotrichoid; E, erysipeloid.

card distance values greater than 0.48 . The 17 zymodemes, including WHO reference strains, within the Viannia group (lower branch of phenogram) could be divided into five main species clusters for L. panamensis, $L$. guyanensis, L. naiffi, L. braziliensis, and L. peruviana. The four species of Leishmania subgenus included in this study (L. mexicana, L. amazonensis, L. major, and L. chagasi) revealed 10 zymodemes (upper branch of phenogram), 10 Ecuadorian isolates were identified as L. amazonensis and two isolates as L. major (Z21). From the eleven isolates identified as L. mexicana involving 4 zymodemes, $\mathrm{Z} 20$ was the only zymodeme identified in 5 out of 8 Uta lesions and confined to Paute. No isolates of Viannia subgenus were found in the inter-Andean region.

\section{Discussion}

The data from this study shows a great diversity of Leishmania species and zymodeme phenotypes isolated from a wide spectrum of clinical forms of ATL in Ecuador. The diversity in the parasite populations may contribute to the highly variable clinical spectrum of leishmaniasis observed in this study and previous studies [13-16,27]. A high degree of enzymatic polymorphisms in Leishmania parasites has been reported previously in Ecuador [20], and also in the neighboring countries of Colombia, Brazil and Peru $[8,9,12]$. The findings of higher molecular diver- sity in species isolated from subtropical and tropical regions of the Pacific coast in this study rather than from the inter-Andean region could be related to the greater number of animal reservoirs and sandfly fauna encountered in these regions $[28,29]$. We report for the first time in Ecuador enzymatic polymorphism of L. amazonensis, $L$. mexicana and L. braziliensis, and have characterized Leishmania from mucocutaneous lesions.

The present study provides evidence that some of the distinct clinical forms of ATL are associated with specific Leishmania species and some may be related with a restricted number of zymodemes. Thus, MCL was associated only with L. braziliensis, LRC and other atypical presentations of CL with L. panamensis and, Uta lesions with L. mexicana. The evidence for associations of specific zymodemes with clinical variants was observed only for LRC and Uta; three zymodemes of L. panamensis associated with all 8 patients with LRC, and 1 zymodeme of $L$. mexicana related with $5 / 8$ cases of Uta. It has been suggested that clades of $L$. braziliensis genotypes may be associated by specific cutaneous, mucosal or disseminated manifestations [9] but our data provides limited evidence for this and is in agreement with other studies [5-8,11]. $L$. braziliensis was the only species isolated from MCL lesions and previous studies in Brazil, Colombia and Peru have 
Table 2: Enzymatic profiles of the 21 zymodemes found in Leishmania isolates from Ecuador

\begin{tabular}{|c|c|c|c|c|c|c|c|c|c|c|c|}
\hline \multirow[b]{2}{*}{ Leishmania spp. and zymodeme } & \multicolumn{11}{|c|}{ Enzymes } \\
\hline & G-6PD & 6-PGD & ME & $\mathrm{MDH}$ & ASAT & ALAT & GPI & MPI & PGM & PK & $\mathrm{NH}$ \\
\hline \multicolumn{12}{|l|}{ L. L. amazonensis } \\
\hline ZI & 2 & 1 & 1 & 2 & 5 & 2 & 3 & 2 & 4 & 2 & 2 \\
\hline $\mathrm{Z2}$ & 2 & 1 & 1 & 2 & 4 & 2 & 3 & 2 & 4 & 2 & 2 \\
\hline \multicolumn{12}{|l|}{ L.V. panamensis } \\
\hline Z3 & 2 & 4 & 2 & 1,5 & 1 & 3 & 1,2 & 4 & 3 & 1 & 1,3 \\
\hline Z4 & 2 & 4 & 2 & 1,5 & 2 & 3 & 1,2 & 4 & 3 & 1 & 1,3 \\
\hline $\mathrm{Z} 5$ & 2 & 4 & 3 & 1,5 & 1 & 3 & 1,2 & 4 & 3 & 1 & 1,3 \\
\hline $\mathrm{Z7}$ & 1 & 3 & 3 & 1,5 & 2 & 3 & 1,2 & 4 & 3 & 1 & 1,3 \\
\hline Z8 & 2 & 4 & 3 & 1,5 & 2 & 3 & 1,2 & 4 & 3 & 1 & 1,3 \\
\hline ZI5 & 1 & 4 & 3 & 1,5 & 1 & 3 & 1,2 & 4 & 2 & 1 & 1,3 \\
\hline Z16 & 2 & 2 & 2 & 1,5 & 1 & 3 & 1,2 & 4 & 3 & 1 & 1,3 \\
\hline \multicolumn{12}{|l|}{ L. V. braziliensis } \\
\hline Z6 & 2 & 3 & 2 & 1,3 & 3 & 4 & 1,2 & 3 & 2 & 3 & $\mathrm{I}, 4$ \\
\hline Z9 & 2 & 3 & 3 & $\mathrm{I}, 3$ & 2 & 6 & 1,2 & 3 & 2 & 3 & $\mathrm{I}, 4$ \\
\hline ZI0 & 2 & 3 & 2 & 1,3 & 2 & 6 & 1,2 & 3 & 2 & 3 & $\mathrm{I}, 4$ \\
\hline \multicolumn{12}{|l|}{ L. V. guyanensis } \\
\hline ZII & I & 2 & 3 & 1,5 & 2 & 3 & 1,2 & 4 & 4 & I & 2,3 \\
\hline $\mathrm{Z} 12$ & 1 & 2 & 3 & 1,5 & 2 & 5 & 1,2 & 4 & 3 & 1 & 2,3 \\
\hline $\mathrm{ZI3}$ & 1 & 2 & 3 & 1,5 & 1 & 4 & 1,2 & 4 & 3 & 1 & 2,3 \\
\hline $\mathrm{ZI} 4$ & 2 & 4 & 3 & 1,5 & I & 4 & 1,2 & 4 & 3 & 1 & 2,3 \\
\hline \multicolumn{12}{|l|}{ L. L. mexicana } \\
\hline ZI7 & 3 & 1 & I & $\mathrm{I}, 3$ & 4 & 1 & 4 & 1 & 1 & 3 & 2,4 \\
\hline $\mathrm{Z} 18$ & 3 & 2 & 3 & 2 & 5 & 1 & 4 & 3 & 2 & 3 & 4,6 \\
\hline $\mathrm{Z} 19$ & 3 & 2 & 3 & 2 & 5 & 1 & 4 & 3 & 1 & 3 & 4,6 \\
\hline Z20 & 4 & 2 & 2 & 3 & 5 & I & 4 & 3 & 2 & 3 & 4,6 \\
\hline \multicolumn{12}{|l|}{ L. L. major } \\
\hline Z21 & 4 & 2 & 4 & $\mathrm{I}$ & 2 & 2 & 2 & 1 & 4 & 3 & 4,6 \\
\hline
\end{tabular}

linked also mucosal involvement to infection with this species $[8,9,30]$.

L. panamensis believed to cause generally cutaneous ulcers [31] in this study was associated with all lesions of LRC and other presentations (i.e., erysipeloid, sporotrichoid, and disseminated). However, the latter lesions were observed only in the Pacific highlands (Andes slopes) and it is possible that factors specific to this environment may contribute to atypical presentations of ATL such as volcanic soil [32].

L. mexicana infection presented in children as small papules (Uta) in the inter-Andean region, lesions that heal spontaneously in a few months leaving an imperceptible scar. L. mexicana isolated in the Andes seems to have a unique life cycle, in which only Lu. ayacuchensis and domestic dogs are incriminated as vector and reservoir, respectively [28,33]. Interestingly, in the Peruvian Andes, a similar clinical presentation is caused by L. peruviana [34]. It has been speculated that UV radiation, which is stronger in the highlands, may also play a role in the outcome of infection [35].
This study demonstrated geographic restriction of some Leishmania species in Ecuador. Leishmania subgenus was generally observed in the inter-Andean region, whereas Viannia was observed generally in forested areas. However, there was some overlap with $L$. mexicana and $L$. major, also being isolated from the Pacific region. L. panamensis was the predominant species identified in the Pacific highlands (76.0\% of all isolates) and L. mexicana predominated in the inter-Andean region (90.9\% of isolates). In general, the geographic distribution of Leishmania species observed in this study is in agreement with previous reports [16,18-20]. Nevertheless, we did not identify any isolates of $L$. braziliensis from the Pacific region, and this finding may explain the rarity of MCL in this region. Although mucosal involvement caused by this and others Viannia species has been reported in the Colombian Pacific coastal [8], we and others clinical investigators have never diagnosed espundia originating in the Pacific coastal area of the country.

Interestingly, L. amazonensis was identified in $17 \%$ of the 56 isolates examined. This figure is higher than previously reported but our data confirmed the wide distribution of 


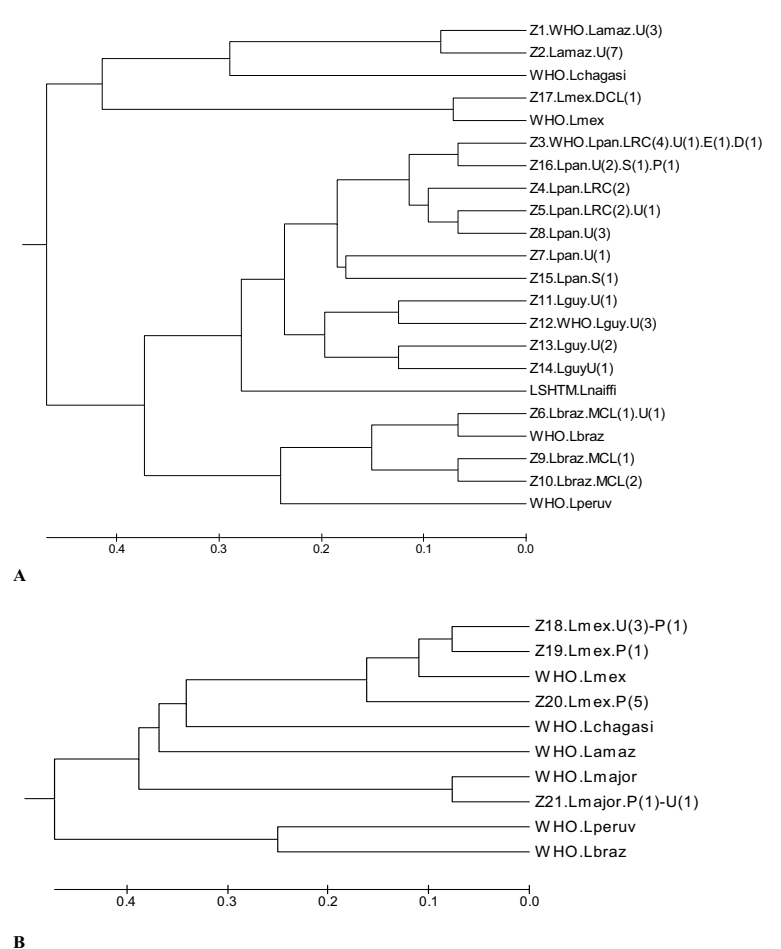

Figure 2

Phenogram of the 56 Ecuadorian Leishmania isolates and 9 WHO reference strains. $2 A$ shows the 17 zymodemes from patients infected in the forest of Pacific and Amazon region. $2 \mathrm{~B}$ shows 4 zymodemes identified from the inter-Andean area. The Leishmania species identified are shown at the end of the branches with the type of clinical lesions and number of subjects in parentheses. Lamaz $-L$. amazonensis, Lbraz - L. braziliensis, Lguy - L. guyanensis, Lmex - L. mexicana, Lpan - L. panamensis, Lperuv - L. peruviana. U, ulcer; DCL, diffuse cutaneous leishmaniasis; LRC, leishmaniasis recidiva cutis; $E$, erysipeloid; $S$, sporotrichoid; $P$, papular or Uta-like, and MCL, mucocutaneous leishmaniasis.

this species in forested areas of the Pacific Ecuador $[13,16,17,19]$ and we identified this species in the Amazon region. The original observation of $L$. major-like infection in Ecuador recorded by Hashiguchi et al., [18] has been confirmed in the present study. Furthermore, we have demonstrated that these parasites belong to different zymodeme of the WHO reference strain (Turkmen, USSR). L. major has been identified also in Brazil, Venezuela, Paraguay and Mexico [9,24,36]. It has been reported that $L$. naiffi is widespread in South American countries [37] with one patient possibly infected in Ecuador. In the current study we were unable to isolate any parasite with phenotypic similarity to the WHO reference stock for this species.

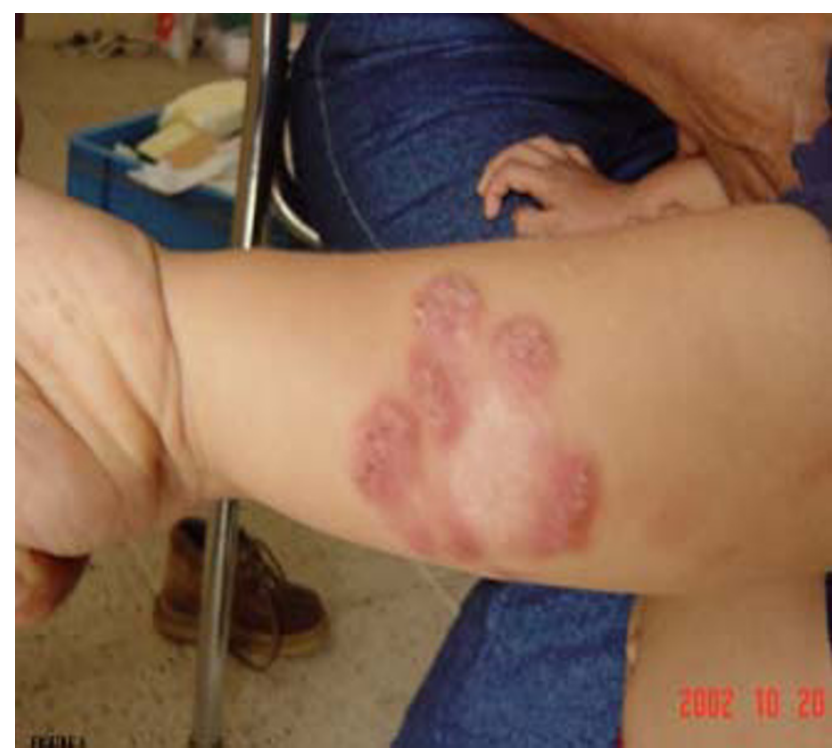

Figure 3

Lesions of Leishmaniasis recidiva cutis (LRC) on the forearm of a 6-years old boy. Red-brown papules appeared around a healed scar and progressed intermittently over a period of 3 years, leaving an extensive depressed scar (center). All parasites isolated from LRC were identified as $L$. (V.) panamensis, entailing $3(\mathrm{Z3}-\mathrm{Z} 5)$ out of 7 zymodemes.

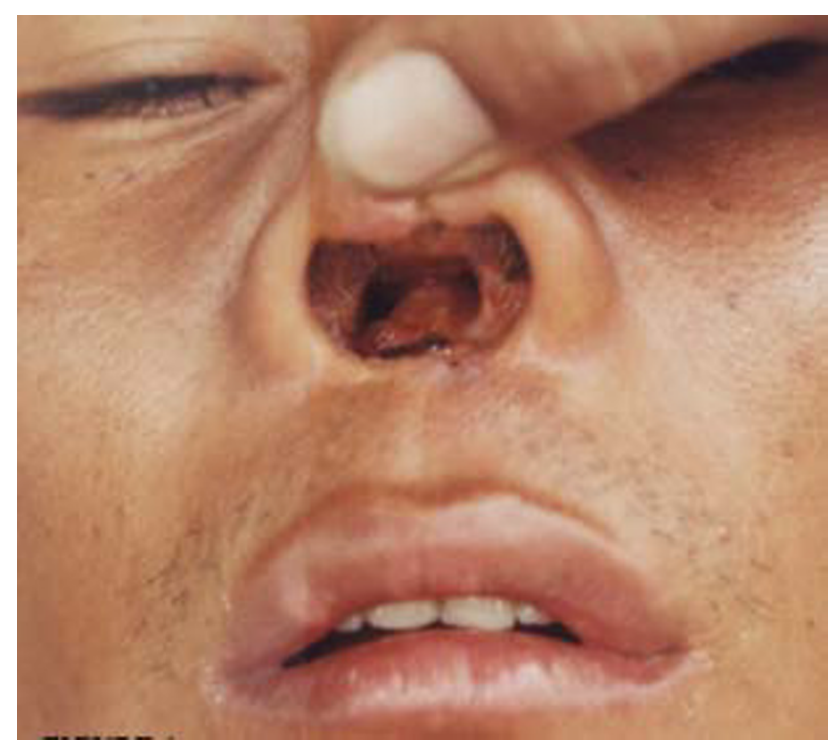

Figure 4

Mucocutaneous leishmaniasis (MCL) or espundia.

Active lesions in nasal mucosal tissue with septal perforation and disfigurement of the nose and swelling of upper lip in a 38-years old man native from the Amazonian lowlands. Parasites from MCL cases were identified as $L$. (V.) braziliensis but no relationship with a specific zymodeme was observed. 


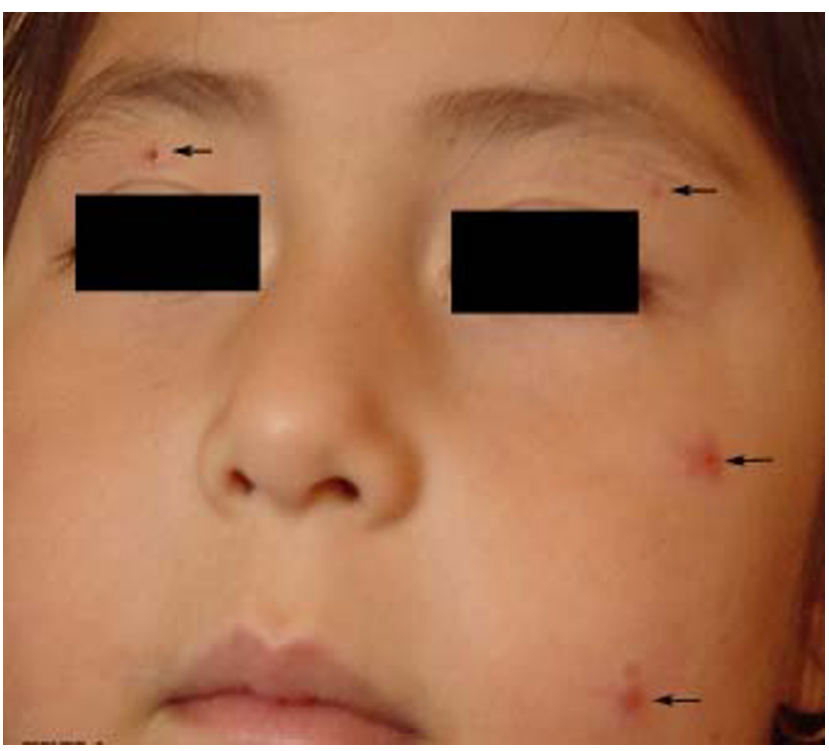

Figure 5

Andean Leishmaniasis or Uta. Four small painless lesions (arrows) in a girl of 5-years old living in the highlands of Ecuadorian Andes. Lesions generally appear on the face of children, and heal within 6 months. All parasites isolated from Uta lesions were $L$. (L.) mexicana with a predominance of zymodeme 20. No mucosal lesions were seen in these foci.

\section{Conclusion}

We have identified six Leishmania species and 21 zymodemes associated with parasites isolated from 56 patients with different clinical forms of leishmaniasis from diverse ecological areas of Ecuador. Our data show a high degree of species and enzymatic polymorphism and some evidence for major clinical presentations of leishmaniasis to be associated with specific Leishmania species but limited evidence with zymodemes. Our data further defines the geographic distribution of leishmaniasis in Ecuador with respect to species distribution and the clinical presentations observed. The mapping of the geographic distribution of Leishmania species and clinical disease will be important both regionally and nationally for designing control programs or interventional field trials for drugs or vaccines.

\section{Competing interests}

The author(s) declare that they have no competing interests.

\section{Authors' contributions}

$\mathrm{MC}$ collected clinical samples, performed the isoenzyme electrophoresis, analyzed data and drafted the manuscript. RXA isolated and cultivated Leishmania parasites at the Central University. JDM, PAB and MK assisted with the isoenzyme electrophoresis. HU, HK, EAG, TM and SN isolated parasites in active field surveys. PJC analyzed data and helped write the manuscript. YH participated in the design of the study and sample collection.

\section{Acknowledgements}

This work was supported by the Ministry of Education, Science Culture and Sports of Japan, grants no. 14256002 and 18256004 . We are indebted to Roberto Sud, Teresa Flor, Jenny Rodriguez, and Yim-Yan Wong Chum for field and laboratory assistance in Ecuador, and to Masato Furuya for maintaining cryopreserved Andean isolates at KMS, Japan. Written consent was obtained from the patients or their relatives for publication of their pictures and data.

\section{References}

I. Calvopina M, Armijos RX, Hashiguchi Y: Epidemiology of Leishmaniasis in Ecuador: Current Status of Knowledge - A Review. Mem Inst Oswaldo Cruz 2004, 99:663-672

2. McMahon-Pratt D: Mechanisms of pathogenesis - Differences amongst Leishmania species. In Report on Leishmaniasis Scientific Working Group Geneva: World Health Organization; 2004:37-39.

3. Handman E, Elso C, Foote S: Genes and Susceptibility to leishmaniasis. In Advances in Parasitology Volume 59. Edited by: Barker JR, Muller R, Rollinson D. London: Elsevier Academic press; 2005: I-75.

4. Handman E: Leishmaniasis: Current status of vaccine development. Clin Microbiol Rev 200I, I 4:229-243.

5. Marco JD, Barroso PA, Calvopina M, Kumazawa H, Furuya M, Korenaga M, Cajal SP, Mora MC, Rea MMJ, Edgardo Borda C, Basombrio MA, Taranto NJ, Hashiguchi Y: Species assignation of Leishmania from human and canine American tegumentary leishmaniasis cases by multilocus enzyme electrophoresis in north Argentina. Am J Trop Med Hyg 2005, 72:606-61I.

6. Reiner NE, Lo R, Llanos-Cuentas A, Guerra H, Button LL, McMaster WR: Genetic heterogeneity in Peruvian Leishmania isolates. Am J Trop Med Hyg 1989, 41:416-421.

7. Rotureau B, Ravel C, Nacher M, Couppié P, Curtet I, Dedet JP, Carme B: Molecular Epidemiology of Leishmania (Viannia) guyanensis in French Guiana. J Clin Microbiol 2006, 44:468-473.

8. Saravia NG, Segura I, Holguin AF, Santrich C, Valderrama L, Ocampo $\mathrm{C}$ : Epidemiologic, genetic, and clinical associations among phenotypically distinct populations of Leishmania (Viannia) in Colombia. Am J Trop Med Hyg 1998, 59:86-94.

9. Schriefer A, Schriefer ALF, Goes-Neto A, Guimaraes LH, Carvalho LP, Almeida RP, Machado PR, Lessa HA, Ribeiro de Jesus A, Riley LW, Carvalho EM: Multiclonal Leishmania braziliensis population structure in a region of endemicity for American tegumentary leishmaniasis. Infect Immun 2004, 72:508-5I4.

10. Shaw Jj: New World leishmaniasis: the ecology of leishmaniasis and the diversity of leishmanial species in Central and South America. In World class parasites. Leishmania Volume 4. Edited by: Farrel JP. USA: Kluwer Academic Pub; 2002:II-3I.

II. Cupolillo E, Brahim LR, Toaldo CB, Paes de Oliveira-Neto M, Felinto de Brito ME, Falqueto A, de Farais Naiff M, Grimaldi G Jr: Genetic polymorphism and molecular epidemiology of Leishmania (Viannia) braziliensis from different hosts and geographic areas in Brazil. J Clin Microbiol 2003, 4 I:3 I 26-3I 32.

12. Dujardin JC, Bañuls AL, Llanos-Cuentas A, Alvarez E, de Doncker S, jacquet D, Le Ray D, Arevalo J, Tibayrenc M: Putative Leishmania hybrids in the Eastern Andean valley of Huanuco, Peru. Acta Trop 1995, 59:293-307.

13. Armijos RX, Weigel MM, Izurieta R, Racines J, Zurita C, Herrera W, Vega M: The epidemiology of cutaneous leishmaniasis in subtropical Ecuador. Trop Med Int Health 1997, 2:|40-52.

14. Chico M, Guderian RH: Caracteristicas fotograficas de las leishmaniasis en el Ecuador. Rev Med Vozandes 1989, 3:56-66.

15. Calvopina M, Gomez EA, Uezato H, Kato H, Nonaka S, Hashiguchi $Y$ : Atypical clinical variants in New World cutaneous leishmaniasis: disseminated, erysipeloid, and recidiva cutis due to Leishmania (V.) panamensis. Am J Trop Med Hyg 2005, 73:28I-284.

16. Armijos RX, Chico ME, Cruz ME, Guderian RH, Kreutzer RD, Berman JD, Rogers MD, Grogl M: Human cutaneous leishmaniasis in Ecuador: identification of parasites by isoenzyme electrophoresis. Am J Trop Med Hyg 1990, 42:424-428. 
17. Furuya M, Akimaru Y, Mimori T, Shiraishi M, Gomez EA, Nonaka S, Hashiguchi Y: Identification of species of Ecuadorian Leishmania isolates by ELISA using monoclonal antibodies. In Studies on New World Leishmaniasis and its transmission with particular reference to Ecuador Volume 5. Edited by: Hashiguchi Y. Kochi Japan: Kyowa Printing; 1997:II-19.

18. Hashiguchi Y, Gomez EA, de Coronel VV, Mimori T, Kawabata M, Furuya M, Nonaka S, Takaoka H, Alexander JB, Quizhpe AM, Grimaldi G Jr, Kreutzer RD, Tesh RB: Andean leishmaniasis in Ecuador caused by infection with Leishmania mexicana and $L$. majorlike parasites. Am J Trop Med Hyg I99I, 44:205-2I7.

19. Mimori T, Grimaldi G Jr, Kreutzer RD, Gomez EA, McMahon-Pratt D, Tesh RB, Hashiguchi Y: Identification using isoenzyme electrophoresis and monoclonal antibodies of Leishmania isolates from humans and wild animals of Ecuador. Am J Trop Med Hyg 1989, 40:154- 158.

20. Bañuls $A L$, Jonquieres R, Guerrini F, Le Pont $F$, Barrera $C$, Espinel I, Guderian R, Echeverria R, Tibayrenc M: Genetic analysis of Leishmania parasites in Ecuador: Are Leishmania (Viannia) panamensis and $L$. (V.) guyanenesis distinct taxa? Am J Trop Med Hyg 1999, 6:838-845.

21. Evans D: Handbook on isolation, characterization and cryopreservation of Leishmania UNDP/World Bank/World Health Organization, Geneva, Switzerland; 1989.

22. Kreutzer RD, Christensen HA: Characterization of Leishmania spp. by isozyme electrophoresis. Am J Trop Med Hyg 1980, 29:199-208.

23. Abderrazak SB, Guerrini F, Mathieu-Daude F, Truc P, Neubauer K, Lewicka K, Barnabe C, Tibayrenc M: Isoenzyme electrophoresis for parasitic characterization. In Protocols in Molecular Parasitology Volume 2I. Edited by: Hyde JE. Totowa, N J: Humana press; 1993:36I-382.

24. Cupolillo E, Grimaldi G Jr, Momen H: A general classification of New World Leishmania using numerical zymotaxonomy. Am J Trop Med Hyg 1994, 50:296-3II.

25. Jaccard P: Nouvelles recherches sur la distribution florale. Bull Soc Vaudoise de Sciences Naturelles 1908, 44:223-270.

26. Kumar S, Tamura K, Nei M: MEGA3: Integrated software for molecular evolutionary genetics analysis and sequence alignment. Brief Bioinform 2004, 5:150-163.

27. Hashiguchi Y, Gomez EA: A review of leishmaniasis in Ecuador. Bull Pan Am Health Organ 199I, 25:64-76.

28. Hashiguchi Y, Gomez EA, de Coronel VV, Mimori T, Kawabata M: Leishmania isolated from wild mammals caught in endemic areas of leishmaniasis in Ecuador. Trans Roy Soc Trop Med Hyg 1985, 79:|20-|2|.

29. Alexander JB, Eshita Y, Gomez EA, Hashiguchi Y: The phlebotomine sandfly fauna (Diptera: Psychodidae) of nine Leishmanic endemic sites in Ecuador. In Studies on New World Leishmaniasis and its transmission with particular reference to Ecuador Volume 3. Edited by: Hashiguchi Y. Kochi Japan: Kyowa Printing; 1992:33-40.

30. Lucas CM, Franke ED, Cachay MI, Tejada A, Cruz ME, Kreutzer RD, Barker DC, McCann SHE, Watt DM: Geographic distribution and clinical description of leishmaniasis cases in Peru. Am J Trop Med Hyg 1998, 59:312-317.

31. World Health Organization: The Leishmaniases. Technical Report Series 70I. Geneva 1984.

32. Convit J, Urlich M, Perez M, Hung J, Castillo J, Rojas H, Viquez A, Araya LN, de Lima H: Atypical cutaneous leishmaniasis in Central America: possible interaction between infectious and environmental elements. Trans $R$ Soc Trop Med Hyg 2005, 99:13-17.

33. Gomez EA, Hashiguchi $Y$ : Monthly variation in natural infection of the sandfly Lu. ayacuchensis with $L$. mexicana in an endemic focus in the Ecuadorian Andes. Ann Trop Med Parasitol 1991, 85:407-4II.

34. Dujardin JC, Llanos-Cuentas A, Caceres A, Arana M, Dujardin JP, Guerrini F, Gomez J, Arroyo J, de Doncker S, Jacquet D, Hamers R, Guerra H, Le Ray D, Arevalo J: Molecular karyotype variation in Leishmania (Viannia) peruviana : indications of geographical populations in Peru distributed along a north-south cline. Ann Trop Med Parasitol 1993, 87:335-347.

35. Nonaka S, Maruno M, Uezato H, Khaskhely NM, Abul KKM, Ramzi ST, Calvopina M, Gomez EA, Hashiguchi Y: Comparison of ultraviolet radiation energy between lowland and highland in Ecuador. Is the skin manifestation of cutaneous leishmania- sis related to ultraviolet radiation? In Studies on New World Leishmaniasis and its transmission with particular reference to Ecuador Volume 6. Edited by: Hashiguchi Y. Kochi Japan: Kyowa Printing; 2001:90-99.

36. Yamasaki H, Agatsuma T, Pavon B, Moran M, Furuya M, Aoki T: Leishmania major-like parasite a pathogenic agent of cutaneous leishmaniasis in Paraguay. Am J Trop Med Hyg 1994, 5 I:749-757.

37. Pratlong F, Deniau M, Darie H, Eichenlaub S, Proll S, Garrabe E, le Guyadec T, Dedet JP: Human cutaneous leishmaniasis caused by Leishmania naiffi is wide spread in South America. Ann Trop Med Parasitol 2002, 96:78I-785.

\section{Pre-publication history}

The pre-publication history for this paper can be accessed here:

http://www.biomedcentral.com/1471-2334/6/139/pre pub
Publish with Biomed Central and every scientist can read your work free of charge

"BioMed Central will be the most significant development for disseminating the results of biomedical research in our lifetime. "

Sir Paul Nurse, Cancer Research UK

Your research papers will be:

- available free of charge to the entire biomedical community

- peer reviewed and published immediately upon acceptance

- cited in PubMed and archived on PubMed Central

- yours - you keep the copyright 